\title{
Existence of low-velocity zones under the source areas of the 2004 Chuetsu and 2007 Chuetsu-oki earthquakes inferred from travel-time tomography
}

\author{
Junichi Nakajima and Akira Hasegawa \\ Research Center for Prediction of Earthquakes and Volcanic Eruptions, Graduate School of Science, Tohoku University, Sendai 980-8578, Japan
}

(Received November 22, 2007; Revised February 13, 2008; Accepted February 26, 2008; Online published November 18, 2008)

\begin{abstract}
Travel-time tomography reveals the presence of highly heterogeneous seismic velocity structures around the source areas of the 2004 Chuetsu and 2007 Chuetsu-oki earthquakes. A prominent low-velocity zone present below the Moho under the source areas of the two events is probably formed by fluids being conveyed through a small-scale upwelling in the mantle wedge. A low-velocity zone distributed in the lower crust below each source area is attributable to fluids supplied from the uppermost mantle to the source area. Since this region with these two source areas is exceptional in that the low-velocity zone is distributed in the uppermost mantle but no Quaternary volcanoes are formed at the surface, a relatively large amount of fluids may be stored below the source areas. These localized fluids may have reduced the strength in the lower crust as well as in the fault zones in the upper crust and, consequently, have promoted a brittle failure in the seismogenic layer. Relocated hypocenters of aftershocks of the two events become several kilometers shallower than the original locations determined by the Japan Meteorological Agency, suggesting the importance of using the three-dimensional velocity model in locating the hypocenter.
\end{abstract}

Key words: Seismic tomography, Chuetsu earthquake, Chuetsu-oki earthquake, low-velocity zone, mantle upwelling, fluids.

\section{Introduction}

The Chuetsu-oki earthquake ( $M$ 6.8) occurred in the Chuetsu region of Niigata Prefecture, Japan, on July 16, 2007 (black star in Fig. 1) and caused serious damage to the surrounding area. The Chuetsu earthquake ( $M$ 6.8) occurred in the same region-approximately $30 \mathrm{~km}$ to the southeast-in 2004 (gray star in Fig. 1), and four aftershocks of magnitude 6 or greater followed the main shock. Kato et al. (2005) and Okada et al. (2005, 2006) reported that the seismic velocities in a hanging wall are lower than those in a footwall in the source area of the 2004 event and argued that aftershocks are distributed around the clear boundary between low and high velocities. Wang and Zhao (2006) found a zone with a pronounced low velocity and high Poisson's ratio in the lower crust of the source area of the 2004 event.

The important point to be addressed here is that both earthquakes occurred in a zone of high strain rates - the Niigata-Kobe Tectonic Zone (NKTZ) (Sagiya et al., 2000). Nakajima and Hasegawa (2007a) revealed the existence of low-velocity zones in the lower crust and uppermost mantle along the NKTZ, but any discussion of velocity structures around the source areas of the two events was difficult because the region is located at the edge of their study area. We therefore estimate three-dimensional (3D) seismic velocity structures of the crust and uppermost mantle in a wider region around the source areas and discuss unique

Copyright (c) The Society of Geomagnetism and Earth, Planetary and Space Sciences (SGEPSS); The Seismological Society of Japan; The Volcanological Society of Japan; The Geodetic Society of Japan; The Japanese Society for Planetary Sciences; TERRAPUB features of the source areas in terms of seismic velocity structures.

\section{Data, Methods, and Resolution Tests}

We performed two tomographic inversions with a different grid spacing to estimate large-scale heterogeneities in the upper mantle and small-scale ones around the source areas of the two events. In both inversions, we used the 3-D tomography method of Zhao et al. (1992a) taking into account crustal discontinuities (Zhao et al., 1992b) and the upper boundary of the Pacific slab (Nakajima and Hasegawa, 2006).

In the first inversion, high-quality $P$ - and $S$-wave arrival times generated from 4,772 earthquakes that occurred during between January 2001 and July 2007 were used (Fig. 1). Arrival times for these earthquakes were manually picked at 473 seismograph stations, and 401,633 $P$ - and 249,870 Swave arrival times were obtained. Grid nodes with a spacing of $0.2^{\circ}$ in the horizontal direction were set up in the model space to express large-scale velocity structures (Fig. 2(a)). Vertical grid nodes were set at depths of $0,5,10,25,40$, $60,80,100,120,140,160,180,200,230,260$, and $300 \mathrm{~km}$. A simplified 1-D velocity structure used routinely by the Japan Meteorological Agency (JMA; Ueno et al., 2002) was adopted as an initial $P$-wave velocity model with a constant $V_{p} / V_{s}$ value of 1.73 . The root mean squares (RMS) of the arrival-time residuals for the initial model, $0.29 \mathrm{~s}$ for $P$ waves and $0.48 \mathrm{~s}$ for $S$-waves, were reduced to $0.20 \mathrm{~s}$ and $0.34 \mathrm{~s}$, respectively, after four iterations.

In the second inversion, we used the arrival times of 3,183 aftershocks of the 2004 Chuetsu earthquake picked at 


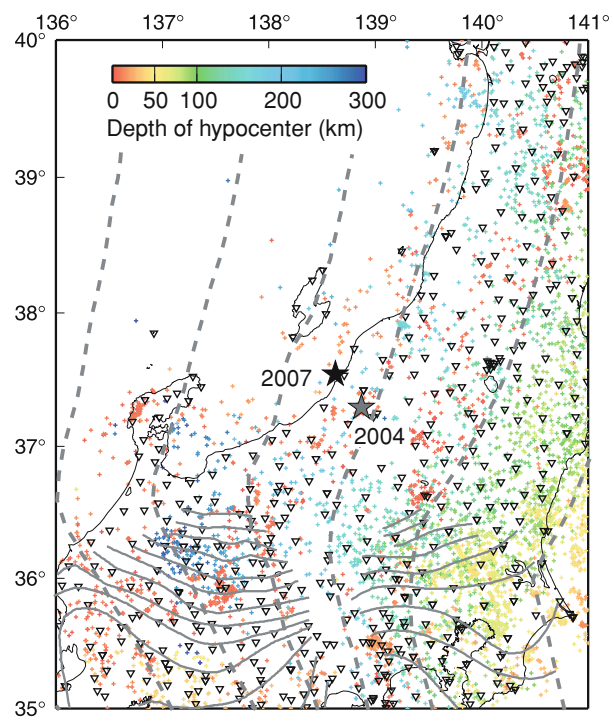

Fig. 1. Locations of the 2004 Chuetsu (a gray star) and 2007 Chuetsu-oki (a black star) earthquakes. Hypocenters and seismograph stations used in the first inversion are shown by crosses and reverse triangles, respectively. Colors represent the depth of the hypocenters.
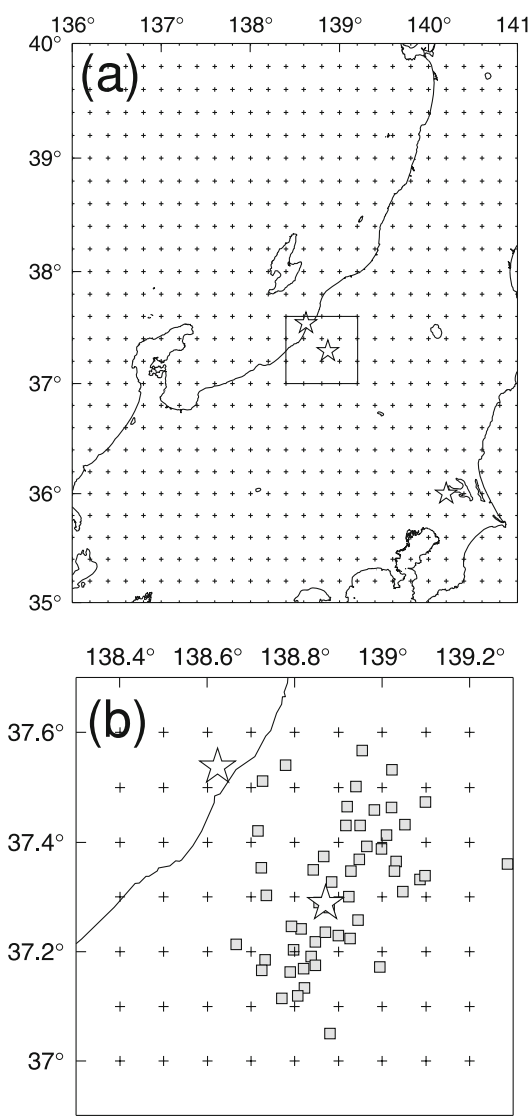

Fig. 2. Map view of the configuration of grid nodes adopted in the (a) first and (b) second inversions. White stars denote the epicenter of the 2004 Chuetsu and 2007 Chuetsu-oki earthquakes. Gray squares in (b) represent temporary stations used in this study (see Okada et al., 2005, 2006, for details).

56 temporary stations within the source area (Fig. 2(b)) and 50 permanent stations located in the wider area in addition to the dataset used in the first inversion. This dataset is the same as that used by Okada et al. (2006) and offers a better (a)

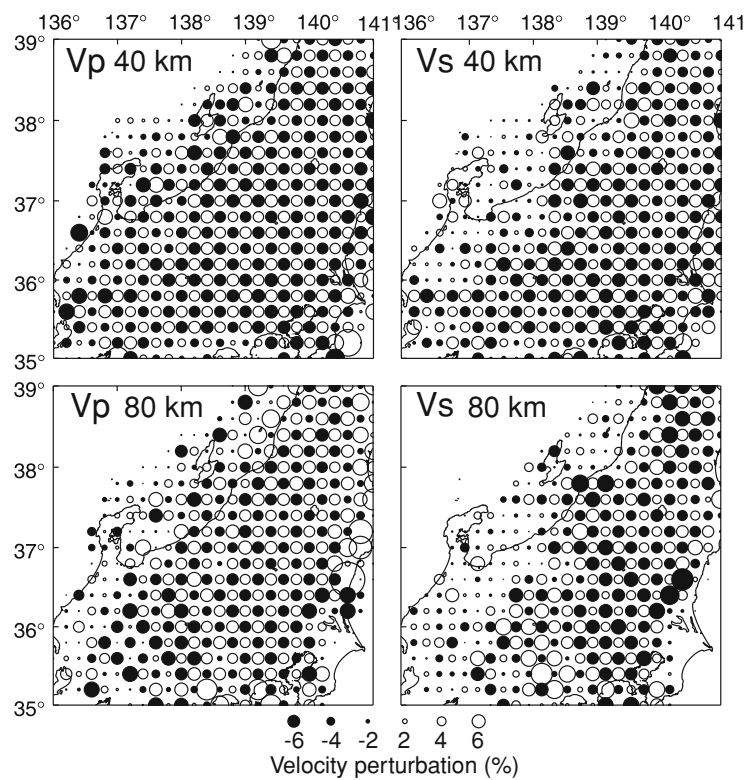

(b)
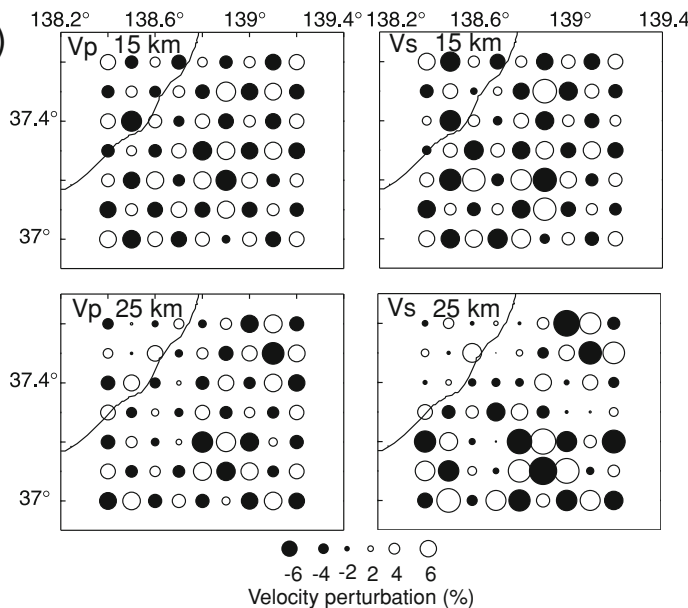

Fig. 3. Results of checkerboard resolution tests of $P$ - and $S$-waves in the (a) first and (b) second inversion for two representative depth layers. Depth of the layer is shown at the left top corner of each figure.

ray coverage around the source area of the 2004 Chuetsu earthquake and surroundings. We set finer grid nodes of a horizontal spacing of $0.1^{\circ}$ down to a depth of $25 \mathrm{~km}$ in and around the source areas of the two events (Fig. 2(b)). To improve the resolution of the velocity images in the mid crust, we also set grid nodes at a depth of $15 \mathrm{~km}$. The 3-D velocity model obtained by the first inversion was adopted as an initial model, and velocity structures only in the region shown in Fig. 2(b) were estimated. The total number of rays intersecting the study area was 153,762 and 126,181 for $P$ - and $S$-waves, respectively. The RMS of the arrivaltime residuals were reduced to $0.12 \mathrm{~s}$ for the $P$-wave and $0.26 \mathrm{~s}$ for the $S$-wave.

We conducted checkerboard resolution tests (CRTs) for the two inversions following Nakajima and Hasegawa (2007a). Figure 3(a) shows the results of the CRTs of the first inversion at depths of 40 and $80 \mathrm{~km}$. Checkerboard patterns were well recovered at both depths beneath the land area, even though the resolution of the $S$-wave is slightly lower in the western part of the study area. The results of the CRTs show that regions beneath the land area show 
good resolutions down to a depth of approximately $140 \mathrm{~km}$. Figure 3(b) shows the results of CRTs of the second inversion in the mid to lower crustal layers (15 and $25 \mathrm{~km}$ depth, repsectively). The resolution is relatively good under the source areas of the two events as well as under surrounding regions, showing the reliability of characteristic velocity structures (discussed in following section).

\section{Results and Discussion}

The seismic velocity images show the existence of a highly heterogeneous structure around the source areas of the two events. Figure 4(a) and (b) shows that low-velocity anomalies are distributed along the volcanic front and in the back-arc side at a depth of $40 \mathrm{~km}$. In particular, a clear image is obtained of a distinct $S$-wave low-velocity zone with a width of approximately $50 \mathrm{~km}$ that extends from the source areas of the two events to the southwest. Lowvelocity zones at a depth of $40 \mathrm{~km}$ are generally correlated spatially with the distribution of Quaternary volcanoes, but the source areas of the two events are exceptional regions in that a prominent $S$-wave low-velocity zone exists in the uppermost mantle but no Quaternary volcanoes are distributed at the surface. The absence of Quaternary volcanoes suggests the possibility of the occurrence of renewed or hidden magmatic activity below the region.

Figure 4(c) shows a vertical cross section of $S$-wave velocity perturbation along the line in Fig. 4(b). A prominent inclined low-velocity zone is distributed in the mantle wedge from a depth of approximately $150 \mathrm{~km}$ in the back-arc side to a depth of $40 \mathrm{~km}$ beneath the volcanic front. This low-velocity zone is a characteristic feature of the mantle wedge in northeastern (NE) Japan and is considered to an important determinant of arc magmatism (Zhao et al., 1992a; Nakajima et al., 2001; Hasegawa and Nakajima, 2004). Interestingly, a distinct low-velocity zone below the Moho under the two source areas appears to be isolated from that identified beneath the volcanic front, and a subvertical low-velocity zone exists at depths of 80-150 km immediately below it. A similar low-velocity zone was also found by Wang and Zhao (2006). It is inferred that this subvertical low-velocity zone is a small-scale mantle upwelling through which melts are probably conveyed to the uppermost mantle under the two source areas. As the sub-vertical upwelling is also observed in the mantle wedge of central Japan, the subduction of the Philippine Sea slab (Nakajima and Hasegawa, 2007b) and/or the change in the strike of the Pacific slab beneath central Japan may have affected the flow pattern in the mantle wedge and caused a small-scale mantle upwelling.

Results of the second inversion show smaller-scale heterogeneities in and around the source areas (Fig. 5). An important point to be noticed is the existence of a low-velocity anomaly in the lower crust under each source area; this is connected to the low-velocity zone in the uppermost mantle. The low-velocity anomaly below the source area of the 2004 event is partly pointed out by Wang and Zhao (2006). One simple interpretation of this low-velocity anomaly is compositional variations in rocks: hydrous rocks, such as amphibolites or hornblende gabbro, can account for a lowvelocity zone (e.g., Nishimoto et al., 2008). Although this
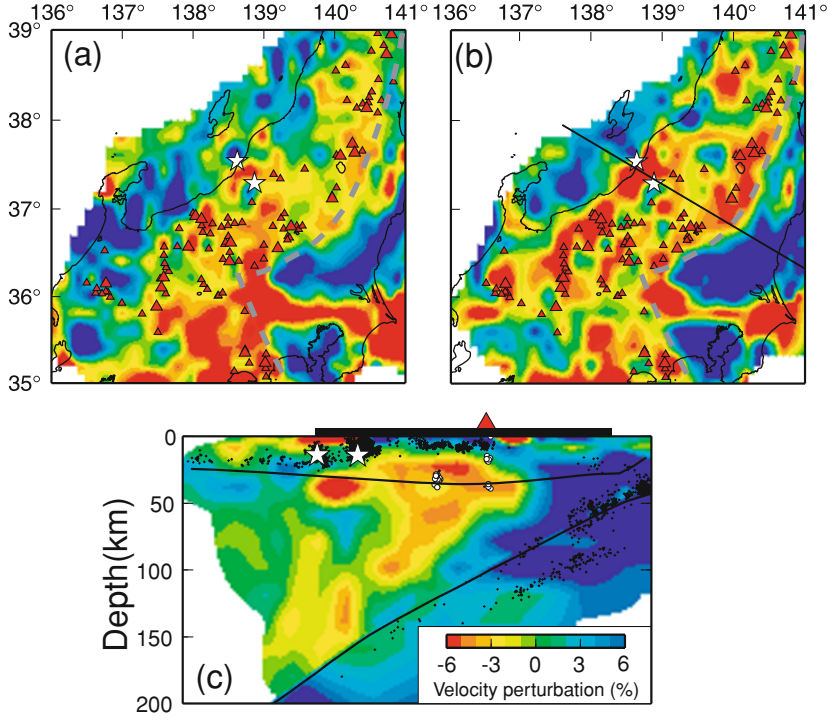

Fig. 4. (a) $P$-wave and (b) $S$-wave velocity perturbations at a depth of $40 \mathrm{~km}$. Large and small red triangles represent active and Quaternary volcanoes, respectively. White stars denote epicenters of the 2004 Chuetsu and 2007 Chuetsu-oki earthquakes. A gray broken curve represents the location of the volcanic front. (c) Vertical cross section of $S$-wave velocity perturbations along the profile shown in (b). Crosses and white circles show microearthquakes and deep low-frequency earthquakes relocated with the 3 -D velocity model within a $10-\mathrm{km}$-wide zone along the profile. Black bars and red triangles on the top denote the land area and active volcanoes, respectively. Black curves in (c) denote the Moho and the upper interface of the subducting Pacific slab adopted in the inversion. Regions with the number of hit counts greater than 1,000 are shown.
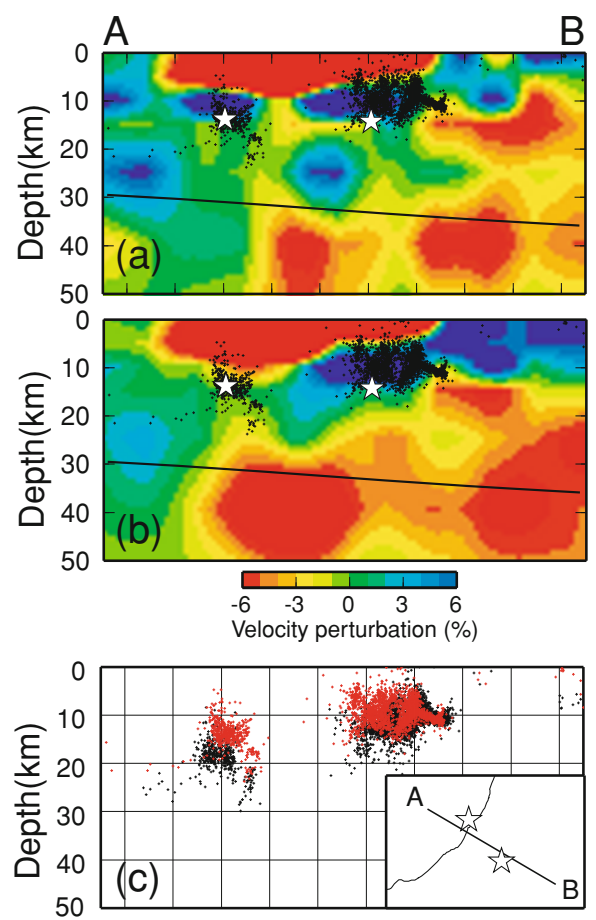

Fig. 5. Vertical cross sections of (a) $P$-wave and (b) $S$-wave velocity perturbations along the profile shown in (c). Crosses denote earthquakes relocated with the 3 -D velocity model within a $2-\mathrm{km}$-wide zone along the profile. Note that earthquakes plotted in figures include smaller earthquakes that are not used in the inversion. Black curve denotes the Moho discontinuity adopted in the inversion. (c) Comparison of hypocenters relocated with the 3-D velocity structures (red crosses) with those in the JMA catalogue (black crosses). 
interpretation is possible, we consider that the existence of fluids beneath the two source areas is a more plausible cause of the low-velocity zone in the lower crust because magmatic fluids can be supplied from the upper mantle to each source area through the sub-vertical upwelling in the mantle wedge. The high heat flow (Tanaka et al., 2004) and high ${ }^{3} \mathrm{He} /{ }^{4} \mathrm{He}$ ratios (Sano and Wakita, 1985) observed around the source areas support our interpretation.

Previous tomographic studies have shown that lowvelocity zones exist below the source areas of large crustal earthquakes, including the 1995 Kobe earthquake (Zhao et al., 1996) and the 2004 Chuetsu earthquake (Okada et al., 2006; Wang and Zhao, 2006). Our study reveals, for the first time, the existence of a low-velocity zone even under the source area of the 2007 Chuetsu-oki earthquake. These observations appear to support the model proposed by Hasegawa et al. (2005) that the existence of fluids in the lower crust and uppermost mantle may have reduced the strength there, which in turn could promote a brittle failure in the seismogenic layer.

We relocated aftershocks of the two main shocks with the $3-\mathrm{D}$ model developed here. Estimated errors in focal depths are about 1-2 km. Relocated hypocenters become approximately $5 \mathrm{~km}$ shallower for aftershocks of the 2007 event and several kilometers shallower for those of the 2004 event than those in the original catalog by the JMA (Fig. 5(c)). The underlying reason for this relocation is the existence of a thick sedimentary basin formed as a back-arc rift basin associated with the opening of the Sea of Japan (e.g., Sato, 1994). The 3-D velocity structures are essential in determining the accurate locations of aftershocks in this region.

\section{Conclusions}

The results of this study successfully elucidate the major features of the complex velocity structures below the source areas of the 2004 Chuetsu and 2007 Chuetsu-oki earthquakes. They reveal that the region including the source areas of the two events is exceptional in that a prominent $S$-wave low-velocity zone exists in the uppermost mantle without Quaternary volcanoes at the surface. A relatively large volume of magmatic fluids might be stored around the source areas. A low-velocity zone imaged in the lower crust below each source area is probably attributable to fluids conveyed through a small-scale mantle upwelling generated in the back-arc side. These observations suggest that the existence of fluids under the source area of large crustal earthquakes plays an important role on anelastic/elastic deformation in the seismogenic layer. It is hoped that the results obtained herein will contribute towards a better understanding of the stress-accumulation processes in the source area of the two large earthquakes.

Acknowledgments. We would like to thank D. Zhao for providing us with the tomography codes. T. Okada gave us relocated aftershocks of the 2004 Chuetsu earthquake. We thank two anonymous reviewers for their constructive comments and suggestions. Waveforms recorded at a nation-wide seismograph network and the JMA-unified catalog are used in this study.

\section{References}

Hasegawa, A. and J. Nakajima, Geophysical constraints on slab subduction and arc magmatism, in The State of the Planet: Frontiers and Challenges in Geophysics, Geophys. Monogr. Ser., 150, 81-94, AGU, Washington, D.C., 2004.

Hasegawa, A., J. Nakajima, N. Umino, and S. Miura, Deep structure of the northeastern Japan arc and its implications for crustal deformation and shallow seismic activity, Tectonophys., 403, 59-75, 2005.

Kato, A., E. Kurashimo, N. Hirata, T. Iwasaki, and T. Kanazawa, Imaging the source region of the 2004 Mid-Niigata prefecture earthquake and the evolution of the seismogenic thrust-related fold, Geophys. Res. Lett., 32, L07307, doi:10.1029/2005GL022366, 2005.

Nakajima, J. and A. Hasegawa, Anomalous low-velocity zone and linear alignment of seismicity along it in the subducted Pacific slab beneath Kanto, Japan: Reactivation of subducted fracture zone?, Geophys. Res. Lett., 33, L16309, doi:10.1029/2006GL026773, 2006.

Nakajima, J. and A. Hasegawa, Deep crustal structure along the NiigataKobe Tectonic Zone, Japan: Its origin and segmentation, Earth Planets Space, 59, e5-e8, 2007a.

Nakajima, J. and A. Hasegawa, Subduction of the Philippine Sea slab beneath southwestern Japan: Slab geometry and its relationship to arc magmatism, J. Geophys. Res., 112, B08306, doi:10. 1029/2006JB004770, 2007b.

Nakajima, J., T. Matsuzawa, A. Hasegawa, and D. Zhao, Threedimensional structure of $V_{p}, V_{s}$ and $V_{p} / V_{s}$ beneath the northeastern Japan arc: Implications for arc magmatism and fluids, J. Geophys. Res., 106, 21843-21857, 2001.

Nishimoto, S., M. Ishikawa, M. Arima, T. Yoshida, and J. Nakajima, Simultaneous high P-T measurements of ultrasonic compressional and shear wave velocities in Ichino-megata mafic xenoliths: Their bearing on seismic perturbations in lower crust of northeast Japan arc, J. Geophys. Res., 2008 (submitted).

Okada, T. et al., Aftershock distribution and 3D seismic velocity structure in and around the focal area of the 2004 mid Niigata prefecture earthquake obtained by applying double-difference tomography to dense temporary seismic network data, Earth Planets Space, 57, 435-440, 2005 .

Okada, T., T. Yaginuma, N. Umino, T. Matsuzawa, A. Hasegawa, H. Zhang, and C. H. Thurber, Detailed imaging of the fault planes of the 2004 Niigata-Chuetsu, central Japan, earthquake sequence by doubledifference tomography, Earth Planet. Sci. Lett., 244, 32-43, 2006.

Sagiya, T., S. Miyazaki, and T. Tada, Continuous GPS array and presentday crustal deformation of Japan, Pageoph, 157, 2303-2322, 2000.

Sano, Y. and H. Wakita, Geographical distribution of ${ }^{3} \mathrm{He} /{ }^{4} \mathrm{He}$ ratios in Japan: Implications for arc tectonics and incipient magmatism, J. Geophys. Res., 90, 8729-8741, 1985.

Sato, H., The relationship between late Cenozoic tectonic events and stress field and basin development in northeast Japan, J. Geophys. Res., 99, 22261-22274, 1994.

Tanaka, A., M. Yamano, Y. Yano, and M. Sasada, Geothermal gradient and heat flow data in and around Japan (I): Appraisal of heat flow from geothermal gradient data, Earth Planets Space, 56, 1191-1194, 2004.

Ueno, H., S. Hatakeyama, T. Aketagawa, J. Funasaki, and N. Hamada, Improvement of hypocenter determination procedures in the Japan Meteorological Agency, Quart. J. Seismol., 65, 123-134, 2002 (in Japanese).

Wang, Z. and D. Zhao, Seismic images of the source area of the 2004 Mid-Niigata prefecture earthquake in Northeast Japan, Earth Planet. Sci. Lett., 244, 16-31, 2006.

Zhao, D., A. Hasegawa, and S. Horiuchi, Tomographic imaging of $P$ and $S$ wave velocity structure beneath northeastern Japan, J. Geophys. Res., 97, 19909-19928, 1992a.

Zhao, D., S. Horiuchi, and A. Hasegawa, Seismic velocity structure of the crust beneath the Japan islands, Tectonophys., 212, 289-301, $1992 \mathrm{~b}$.

Zhao, D., H. Kanamori, H. Negishi, and D. Wiens, Tomography of the source area of the 1995 Kobe earthquake: Evidence for fluids at the hypocenter?, Science, 274, 1891-1894, 1996.

J. Nakajima (e-mail: nakajima@aob.geophys.tohoku.ac.jp) and A Hasegawa 